\title{
Changes in renal function following nedaplatin-containing chemotherapy in patients with urothelial carcinoma unfit for cisplatin
}

\author{
MASAYUKI NAGASAWA, SUSUMU KAGEYAMA, TETSUYA YOSHIDA, YUKI OKINAKA, \\ SHIGEHISA KUBOTA, AKINORI WADA, KENICHI KOBAYASHI, KEIJI TOMITA, RYOSUKE MURAI, \\ TERUHIKO TSURU, KAZUYOSHI JOHNIN, MITSUHIRO NARITA and AKIHIRO KAWAUCHI
}

Department of Urology, Shiga University of Medical Science, Otsu, Shiga 520-2192, Japan

Received August 30,2018; Accepted December 10, 2018

DOI: $10.3892 / 01.2018 .9859$

\begin{abstract}
The present study evaluated the impact of nedaplatin-containing chemotherapy on renal function in 35 patients with urothelial carcinoma (UC) between 2001 and 2014 who were unfit for cisplatin treatment. As comparative controls, the present study also examined 35 patients with the same disease who underwent cisplatin-containing chemotherapy during the same period. The changes in the estimated glomerular filtration rate (eGFR) prior to and following the administration of nedaplatin during each cycle of chemotherapy was investigated. The present study also reported the overall response rates and adverse events in each group. A total of 31 cycles of the gemcitabine/nedaplatin regimen and 66 cycles of the methotrexate/epirubicin/nedaplatin regimen were administered. In the nedaplatin group, the mean eGFRs prior to and following chemotherapy were 45.4 and $47.8 \mathrm{ml} / \mathrm{min} / 1.73 \mathrm{~m}^{2}$, respectively. The eGFR of the post-chemotherapy group was significantly increased $(\mathrm{P}<0.001)$. On the other hand, in the cisplatin group, the eGFR following chemotherapy was significantly lower than the rate prior to chemotherapy $(\mathrm{P}<0.001)$. The overall response rates were 30.4 and $66.7 \%$ in the nedaplatin and cisplatin groups, respectively. In the two groups, myelosuppression was the most common side effect, but the occurrence rates in both groups were similar, and these adverse events were manageable. With regard to nephrotoxicity, nedaplatin-containing chemotherapy for cisplatin-unfit patients with UC is a safe treatment modality.
\end{abstract}

Correspondence to: Dr Susumu Kageyama, Department of Urology, Shiga University of Medical Science, Seta Tsukinowa-cho, Otsu, Shiga 520-2192, Japan

E-mail: kageyama@belle.shiga-med.ac.jp

Key words: chemotherapy, cisplatin-unfit, nephrotoxicity, nedaplatin, urothelial carcinoma

\section{Introduction}

Systematic chemotherapy has been the mainstay of treatment for advanced urothelial carcinoma (UC). Cisplatin-containing combination therapy is considered as standard first-line chemotherapy. However, many patients with advanced UC have renal dysfunction and poor performance status (1). Due to the nephrotoxicity and gastrointestinal toxicity associated with cisplatin, many patients are often unfit for drug treatment, with the proportion in various cohorts ranging from $30-60 \%(2,3)$. Carboplatin is frequently substituted for cisplatin, although its therapeutic efficacy is reportedly inferior to that of cisplatin (4). To date, no standard therapy for cisplatin-unfit patients has been established.

Nedaplatin is a platinum derivative that was developed in Japan. It is more soluble than cisplatin, and has less side effects in terms of renal function and gastrointestinal symptoms (5). Nedaplatin has antitumor activity in various cancer types, such as head and neck cancer, lung cancer, cervical cancer, and ovarian cancer. In advanced UC, the response rate with nedaplatin alone is $28.6 \%$. In terms of renal toxicity, serum creatinine elevation is observed in $15.1 \%$ of the patients (6). However, the anticancer effect and the impact on renal function of nedaplatin is poorly understood when it is included as part of a combination regimen in UC.

To determine the extent of renal toxicity associated with nedaplatin-containing combination chemotherapy, we designed the current study to evaluate changes in renal function of nedaplatin combination regimens in patients with advanced UC.

\section{Materials and methods}

Patients. A total of $35 \mathrm{UC}$ patients who had received nedaplatin-containing chemotherapy at the Shiga University of Medical Science Hospital from 2001 to 2014 were studied retrospectively. As comparative controls, we also examined 35 patients with the same disease who underwent cisplatin-containing chemotherapy during the same period. The eligibility criteria were as follows 1): UC with local invasion or metastasis, 2) cisplatin ineligible due to impaired renal 
function, 3) cisplatin-related adverse events during previous chemotherapy, and 4) an Eastern Cooperative Oncology Group (ECOG) performance status of 2 or less. In our institution, a cutoff value of measured creatinine clearance $<60 \mathrm{ml} / \mathrm{min}$ was used to exclude patients from receiving cisplatin-containing chemotherapy.

The present study was approved by the ethics review board of Shiga University of Medical Science (Shiga, Japan).

Nedaplatin-containing regimens and treatment schedule. Cisplatin was replaced with nedaplatin in select combination regimens. Two regimens were performed. One was methotrexate/epirubicin/nedaplatin(MEN)therapy,whichis essentially a modified version of methotrexate/epirubicin/cisplatin (MEC) therapy (7). The other was gemcitabine/nedaplatin (GN) therapy, which was based on a modification of gemcitabine/cisplatin (GC) therapy (8). Patients who were given MEN therapy received methotrexate $\left(30 \mathrm{mg} / \mathrm{m}^{2}\right)$ on days 1 and 15 , epirubicin $\left(50 \mathrm{mg} / \mathrm{m}^{2}\right)$ on day 1 and nedaplatin $\left(80 \mathrm{mg} / \mathrm{m}^{2}\right)$ on day 2 intravenously (Fig. 1). Patients given GN therapy received gemcitabine $\left(1,000 \mathrm{mg} / \mathrm{m}^{2}\right)$ on days 1,8 and 15 and nedaplatin $\left(80 \mathrm{mg} / \mathrm{m}^{2}\right)$ on day 1 intravenously. Both regimens were repeated every 4 weeks. Physicians reduced the dose of nedaplatin based on the occurrence of severe hematologic toxicity and/or compromised renal function.

Evaluationofrenalfunctionand therapeutic effect. Wecompared estimated glomerular filtration rate (eGFR; $\mathrm{ml} / \mathrm{min} / 1.73 \mathrm{~m}^{2}$ ) before and after each cycle of chemotherapy. The eGFR after administration was assessed just before the next cycle, and was calculated using the following formula reported by the Japanese Society of Nephrology in 2008. eGFR $=194 \times \mathrm{Cr}^{-1.094} \times \mathrm{Age}^{-0.287}$ if male, or $194 \times \mathrm{Cr}^{-1.094} \mathrm{xAge} \mathrm{A}^{0.739}$ if female (9).

Therapeutic effects were evaluated using the response rate according to the Response Evaluation Criteria in Solid Tumors (10). Toxicity was monitored according to Common Terminology Criteria for Adverse Events (CTCAE) v.4.0.

Statistical analysis. Differences between patients' characteristics were estimated using a chi-square test and an independent sample t test. Paired t tests were used to compare changes of eGFR between pre- and post-administration in each cycle of chemotherapy. All data were analyzed using SPSS software (v.22; IBM Corp., Armonk, NY, USA) and $\mathrm{P}<0.05$ was considered to indicate a statistically significant difference.

\section{Results}

Patients' characteristics. Patients' characteristics are shown in Table I. The primary tumors in both groups were four cases of renal pelvic carcinoma (11\%), 13 cases of ureter carcinoma $(37 \%)$ and 18 cases of bladder carcinoma (51\%). The median ages of patients who underwent nedaplatin combination regimen (nedaplatin group) and cisplatin combination regimen (cisplatin group) were 64 and 68 years, respectively; this difference was not statistically significant. On the other hand, the performance status was significantly poorer in the nedaplatin group than in the cisplatin group.

All patients of the cisplatin group and $97 \%$ (34 of 35) of the nedaplatin group received these drugs as first-line therapy.
In the nedaplatin group, approximately half of patients had received a prior cisplatin combination regimen (57\%) and were switched to nedaplatin due to cisplatin-unfitness. Only one case was treated as the second-line therapy for relapse after a prior cisplatin combination regimen.

Patients treated with the nedaplatin combination regimen underwent 66 cycles of MEN therapy and 31 cycles of GN therapy. The most common reason for using nedaplatin was chronic renal failure (18 cases, 51\%); the second was impaired renal function caused by the cisplatin combination regimen (13 cases, $37 \%$ ). Twenty-four patients had an eGFR of 30-60 ml/min $/ 1.73 \mathrm{~m}^{2}$, and four patients had an eGFR of less than $30 \mathrm{ml} / \mathrm{min} / 1.73 \mathrm{~m}^{2}$ before induction of nedaplatin chemotherapy.

Changes in renal function before and after chemotherapy. We compared changes in eGFR at each cycle of chemotherapy (Fig. 2). In the nedaplatin group ( $n=97$ cycles), the mean eGFRs before and after chemotherapy were $45.4 \mathrm{ml} / \mathrm{min} / 1.73 \mathrm{~m}^{2}$ and $47.8 \mathrm{ml} / \mathrm{min} / 1.73 \mathrm{~m}^{2}$, respectively. The post-chemotherapy eGFR was significantly increased $(\mathrm{P}<0.001)$. The eGFR in the nedaplatin group was significantly elevated, even when cases with eGFR $<60 \mathrm{ml} / \mathrm{min} / 1.73 \mathrm{~m}^{2}$ were analyzed ( $n=87$ cycles). On the other hand, in the cisplatin group ( $n=169$ cycles), the mean eGFRs before and after chemotherapy were $51.0 \mathrm{ml} / \mathrm{min} / 1.73 \mathrm{~m}^{2}$ and $48.5 \mathrm{ml} / \mathrm{min} / 1.73 \mathrm{~m}^{2}$, respectively. This decrease was statistically significant $(\mathrm{P}<0.001)$. As a sub-analysis in the nedaplatin group, eGFR alterations in patients whose renal function was impaired by prior cisplatin administration were investigated ( $n=33$ cycles in 13 patients). No decrease in renal function following nedaplatin administration was observed in this sub-population (Fig. 3). In a subgroup of patients where nedaplatin dose reduction was not required, the mean eGFR values before and after chemotherapy were $59.2 \mathrm{ml} / \mathrm{min} / 1.73 \mathrm{~m}^{2}$ and $63.2 \mathrm{ml} / \mathrm{min} / 1.73 \mathrm{~m}^{2}$, respectively ( $n=16$ cycles in 11 patients). Thus, renal function was not compromised in patients receiving the standard full dose of nedaplatin.

Treatment evaluation. In the nedaplatin group, the median number of times the nedaplatin combination regimens administered was two cycles (1-8 cycles, Table II). The median dose of nedaplatin per cycle was $60.0 \mathrm{mg} / \mathrm{m}^{2}$, and the median relative dose intensity (RDI) was $63.0 \%$. In the cisplatin group, RDI and number of chemotherapy cycles were significantly larger than in the nedaplatin group $(\mathrm{P}<0.001)$. Of the 23 patients who had measurable lesions in the nedaplatin group, one complete response (CR) (4.3\%) and six partial responses (PRs) $(26.1 \%)$ were observed. The overall response rate (CR+PR) was $30.4 \%$ in the nedaplatin group, and $66.7 \%$ in the cisplatin group. The overall response rate of all cases and metastatic cases was higher in the cisplatin group than in the nedaplatin group $(\mathrm{P}<0.001)$. In the nedaplatin group, the overall response rates in patients with and without prior cisplatin chemotherapy were $23.1 \%$ (3 of 13 cases) and $40.0 \%$ (4 of 10 cases), respectively.

Adverse events. In both groups, myelosuppression was the most common side effect (Table III). Leucopenia of Grade 3 or more was observed in 68.6 and $65.7 \%$ in the cisplatin and nedaplatin groups, respectively. The incidence of febrile neutropenia also occurred at frequencies of 20.0 and $22.9 \%$ in the cisplatin and nedaplatin groups, respectively. The incidences of Grade 2 
Table I. Patients' characteristics.

\begin{tabular}{|c|c|c|c|}
\hline Characteristic & $\begin{array}{l}\text { Cisplatin } \\
\text { group }\end{array}$ & $\begin{array}{l}\text { Nedaplatin } \\
\text { group }\end{array}$ & P-value \\
\hline Age (years) & & & 0.052 \\
\hline Median & 68 & 64 & \\
\hline Range & $55-82$ & $54-83$ & \\
\hline $\operatorname{Sex}(n)$ & & & 0.78 \\
\hline Male & 26 & 27 & \\
\hline Female & 9 & 8 & \\
\hline $\begin{array}{l}\text { ECOG Performance } \\
\text { status (n) }\end{array}$ & & & $0.02^{\mathrm{a}}$ \\
\hline 0 & 15 & 8 & \\
\hline 1 & 20 & 20 & \\
\hline 2 & 0 & 7 & \\
\hline Primary site (n) & & & 1 \\
\hline Upper urinary tract & 17 & 17 & \\
\hline Bladder & 18 & 18 & \\
\hline $\begin{array}{l}\text { Purpose of } \\
\text { chemotherapy (n) }\end{array}$ & & & 0.15 \\
\hline Neoadjuvant & 10 & 5 & \\
\hline Adjuvant & 10 & 16 & \\
\hline Metastasis & 25 & 18 & \\
\hline \multicolumn{4}{|l|}{$\begin{array}{l}\text { Prior chemotherapy, } \\
\text { n (cycles) }\end{array}$} \\
\hline None & & 17 & \\
\hline MEC & & $13(21)$ & \\
\hline $\mathrm{GC}$ & & $9(36)$ & \\
\hline \multicolumn{4}{|l|}{ Regimen (cycles) } \\
\hline MEC & 24 & 66 & \\
\hline $\mathrm{GC} / \mathrm{GN}$ & 145 & 31 & \\
\hline
\end{tabular}

${ }^{a} \mathrm{P}<0.05$. MEN, methotrexate/epirubicin/nedaplatin therapy; GN, gemcitabine/nedaplatin therapy; GC, gemcitabine/cisplatin therapy; ECOG, Eastern Cooperative Oncology Group.

and 3 acute kidney injuries were $8.6 \%$ (3 patients) and $2.9 \%$ (1 patient) in the cisplatin group, whereas in the nedaplatin group there was no acute kidney injury of Grade 2 or higher. The frequency of gastrointestinal side effects such as anorexia was lower in the nedaplatin group than in the cisplatin group, although this difference was not statistically significant.

\section{Discussion}

Cisplatin combination chemotherapy is a standard treatment for advanced UC. However, many patients with advanced UC are unfit for cisplatin therapy, and standard treatments for such patients have not been established. The proportion of cisplatin-unfit patients due to renal impairment is $28 \%$ in patients with advanced bladder cancer. In upper urinary tract cancer, 51 and $81 \%$ of patients had renal dysfunction before and after nephroureterectomy $(2,3)$. For cisplatin-unfit patients, EAU guidelines recommend

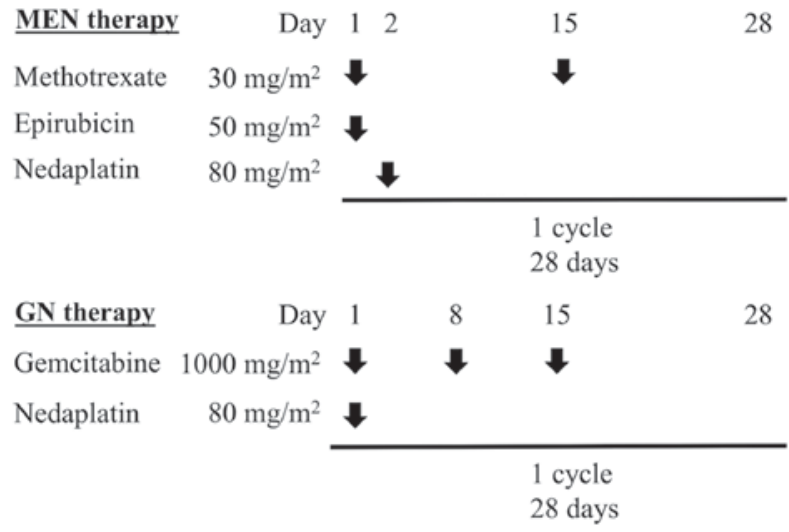

Figure 1. Treatment scheme of the nedaplatin combination regimen. MEN methotrexate/epirubicin/nedaplatin therapy; GN, gemcitabine/nedaplatin therapy.

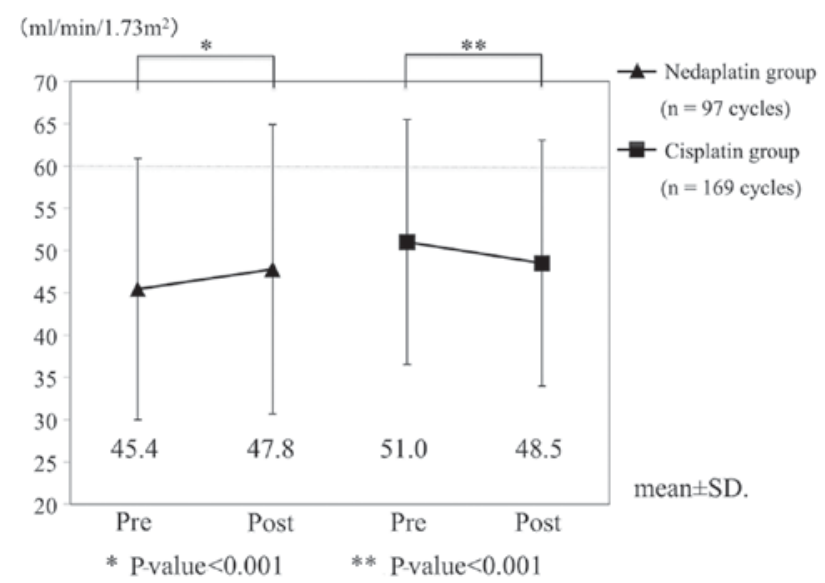

Figure 2. Changes in renal function associated with chemotherapy in the nedaplatin and cisplatin groups. ${ }^{*} \mathrm{P}<0.05$ and ${ }^{* *} \mathrm{P}<0.01$, as indicated. SD, standard deviation; Pre, pre-chemotherapy; Post, post-chemotherapy.

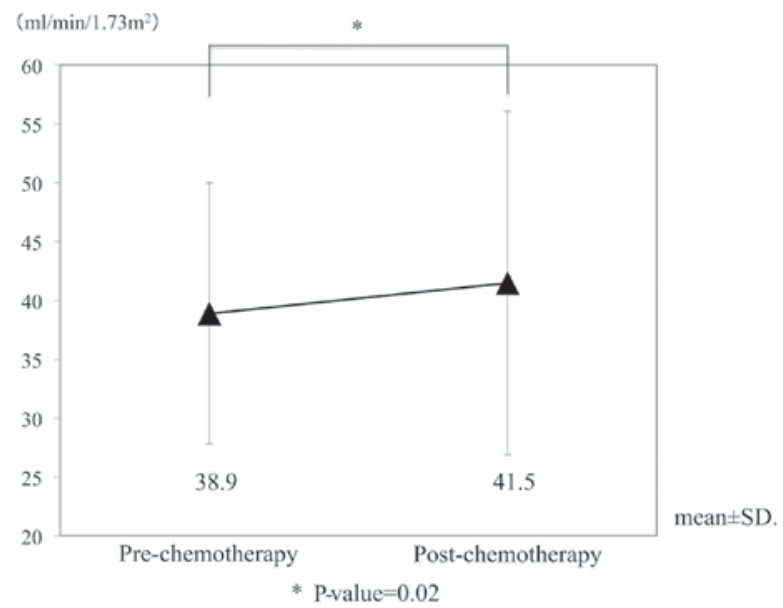

Figure 3. Changes in renal function associated with nedaplatin administration in patients who had experienced kidney injury following the previous administration of cisplatin combination therapy ( $\mathrm{n}=33$ cycles). ${ }^{*} \mathrm{P}<0.05$, as indicated. SD, standard deviation.

carboplatin combination regimens, and particular those that incorporate gemcitabine (11). However, the overall response 
Table II. Amount of treatment and best overall response.

\begin{tabular}{|c|c|c|c|}
\hline Variable & Cisplatin group & Nedaplatin group & P-value \\
\hline \multicolumn{4}{|l|}{ Relative dose intensity (\%) } \\
\hline Median & 96.3 & 63 & \\
\hline Range & $50-100$ & $34.5-143.0$ & $0.0004^{b}$ \\
\hline \multicolumn{4}{|l|}{ Number of cycle (cycles) } \\
\hline Median & 4 & 2 & \\
\hline Range & $1-13$ & $1-8$ & $0.0008^{b}$ \\
\hline \multicolumn{4}{|l|}{ Overall response rate, $\%(n)$} \\
\hline All cases & $66.7(20)$ & $30.4(7)$ & $0.0090^{\mathrm{a}}$ \\
\hline Metastatic cases & $65(13)$ & $22.2(4)$ & $0.0080^{\mathrm{a}}$ \\
\hline Neoadjuvant chemotherapy cases & $70(7)$ & $60(3)$ & 0.7000 \\
\hline
\end{tabular}

${ }^{\mathrm{a}} \mathrm{P}<0.01 ;{ }^{\mathrm{b}} \mathrm{P}<0.001$.

Table III. Adverse Events (Common Terminology Criteria for Adverse Events version 4.0, Grade 3 and above).

\begin{tabular}{|c|c|c|c|c|c|}
\hline \multirow[b]{2}{*}{ Adverse event } & \multicolumn{2}{|c|}{ Cisplatin group } & \multicolumn{2}{|c|}{ Nedaplatin group } & \multirow[b]{2}{*}{$\mathrm{P}$-value } \\
\hline & No. & $\%$ & No. & $\%$ & \\
\hline \multicolumn{6}{|l|}{ Myelosuppression } \\
\hline Anemia & 17 & 48.6 & 18 & 51.4 & 0.810 \\
\hline Leukopenia & 24 & 68.6 & 23 & 65.7 & 0.800 \\
\hline Thrombocytopenia & 25 & 71.4 & 17 & 48.6 & 0.051 \\
\hline Febrile neutropenia & 7 & 20.0 & 8 & 22.9 & 0.770 \\
\hline Nausea & 0 & 0 & 1 & 2.9 & 0.310 \\
\hline Anorexia & 5 & 14.3 & 1 & 2.9 & 0.088 \\
\hline Oral mucositis & 0 & 0 & 1 & 2.9 & 0.310 \\
\hline Colonic obstruction & 1 & 2.9 & 0 & 0 & 0.310 \\
\hline Acute kidney injury & 1 & 2.9 & 0 & 0 & 0.310 \\
\hline
\end{tabular}

rate of gemcitabine and carboplatin combination therapy for cisplatin-unfit metastatic UC is reported as $42 \%$, and antitumor efficacy is limited (1).

Nedaplatin was developed in Japan to provide a treatment with a similar efficacy to cisplatin, but with less renal and gastrointestinal toxicities (5). Nedaplatin is approximately 10 -fold more water-soluble than cisplatin, and this in part explains its reduced nephrotoxicity. Nedaplatin combination therapy elicited less nephrotoxicity than did cisplatin combination therapy. In the present study, no decrease in eGFR was observed after administration of the nedaplatin combination regimen; rather, eGFR was significantly increased. Similar renal function changes were found not only in the cases with eGFR $<60 \mathrm{ml} / \mathrm{min} / 1.73 \mathrm{~m}^{2}$, but also in the case with renal failure due to previous cisplatin chemotherapy. On the other hand, the cisplatin combined regimen reduced eGFR, indicating that nedaplatin is less nephrotoxic compared to cisplatin, and thus safe to use in patients with renal impairment. Regarding the increase of eGFR in the nedaplatin group, it is unlikely that nedaplatin itself had a positive effect on renal function. There were three cases in which hydronephrosis was improved due to the therapeutic effect of nedaplatin, and cases who had improved renal function over time after acute renal failure following cisplatin administration. We infer that these cases affected the significant increase in eGFR after nedaplatin combination regimen.

In the present study, the overall response rate was lower than that observed in other reports of nedaplatin (Table IV) $(6,12-14)$. This may be due to a difference in the drugs that were used in combination with nedaplatin. We currently use gemcitabine in combination with nedaplatin, because an in vivo study suggested a synergistic inhibition of lung cancer cell growth using this combination (15). However, it is unknown whether synergy between nedaplatin and gemcitabine would also be observed in UC. In a meta-analysis of non-small cell lung cancer, docetaxel or paclitaxel plus nedaplatin produced a longer overall and progression-free survival than gemcitabine plus nedaplatin (16). In other studies, nedaplatin was used in combination with paclitaxel to treat UC $(12,13)$, which is different from the combinations used in our regimens. We note that patients with lymph node 
metastasis alone are generally more responsive to anticancer drugs than patients with visceral metastases. Our study had fewer cases with lymph node metastasis alone, which may have masked any association between this disease stage and treatment efficacy. Thirdly, 57\% of patients in our nedaplatin group had previously received treatment with a cisplatin combination regimen. Nedaplatin has the same amine carrier ligand as cisplatin, binds to DNA, and inhibits DNA replication and transcription in a similar manner to cisplatin. Therefore, cross-resistance to nedaplatin can be induced by prior cisplatin treatment (5), and in this study the overall response rate of patients after a cisplatin containing regimen was as low as $23.1 \%$. Finally, a low median dose of $60.0 \mathrm{mg} / \mathrm{m}^{2}$ may lead to a decrease in response rate, although the nedaplatin setting dose is $80.0 \mathrm{mg} / \mathrm{m}^{2}$.

There was no significant difference in the incidence of adverse events induced by cisplatin and nedaplatin. Among the adverse events, the frequency of bone marrow suppression was the highest. Some patients developed febrile neutropenia and required platelet transfusions, but these adverse events were manageable in both groups.

There are some limitations in our study. First, it is a retrospective analysis, and the RDI of the nedaplatin group was low. Therefore, the apparent antitumor efficacy of nedaplatin is comparatively weak. Second, our data were obtained from a small number of patients at a single institution. Third, carboplatin-containing chemotherapy is the most used for cisplatin-unfit patients, but there has been no study comparing the efficacy of carboplatin with that of nedaplatin. We therefore propose that future prospective studies should directly compare the efficacy and safety of nedaplatin and carboplatin.

In conclusion, nedaplatin-containing chemotherapy for cisplatin-unfit patients with advanced UC can be performed safely and is not associated with renal toxicity. Nedaplatin-containing chemotherapy may be available for cisplatin-unfit patients with cancer types other than UC. In order to optimize the use of nedaplatin as an alternative to cisplatin, the optimal drug combinations and the appropriate dose setting of nedaplatin should be elucidated in order to improve its antitumor effect.

\section{Acknowledgements}

Not applicable.

\section{Funding}

The present study was supported in part by a Grant in Aid for Young Scientists (B) from JSPS KAKENHI (grant no. 17K16787).

\section{Availability of data and material}

The data generated during the current study are available from the corresponding author on reasonable request.

\section{Authors' contributions}

MaN, SuK and AK conceived and designed the present study. MaN, TY, YO, ShK, AW, KT, KK, RM and TT obtained the 
patients' data and performed experiments/evaluations. MaN $\mathrm{SuK}, \mathrm{KJ}$ and $\mathrm{MiN}$ analyzed and interpreted the data. MaN and SuK drafted the manuscript. SuK, KJ, MiN and AK revised the manuscript. SuK and AK supervised the study. MaN acquired funding. All authors have read and approved the final manuscript.

\section{Ethics approval and consent to participate}

The present study was approved by the ethics review board of Shiga University of Medical Science (Shiga, Japan) and was performed in accordance with the Declaration of Helsinki.

\section{Patient consent for publication}

Not applicable.

\section{Competing interests}

The authors declare that they have no competing interests.

\section{References}

1. De Santis M, Bellmunt J, Mead G, Kerst JM, Leahy M, Maroto P, Gil T, Marreaud S, Daugaard G, Skoneczna I, et al: Randomized phase II/III trial assessing gemcitabine/carboplatin and methotrexate/carboplatin/vinblastine in patients with advanced urothelial cancer who are unfit for cisplatin-based chemotherapy: EORTC study 30986. J Clin Oncol 30: 191-199, 2012.

2. Dash A, Galsky MD, Vickers AJ, Serio AM, Koppie TM, Dalbagni $G$ and Bochner BH: Impact of renal impairment on eligibility for adjuvant cisplatin-based chemotherapy in patients with urothelial carcinoma of the bladder. Cancer 107: 506-513, 2006.

3. Kaag MG, O'Malley RL, O'Malley P, Godoy G, Chen M, Smaldone MC, Hrebinko RL, Raman JD, Bochner B, Dalbagni G, et al: Changes in renal function following nephroureterectomy may affect the use of perioperative chemotherapy. Eur Urol 58: 581-587, 2010

4. Galsky MD, Chen GJ, Oh WK, Bellmunt J, Roth BJ, Petrioli R, Dogliotti L, Dreicer R and Sonpavde G: Comparative effectiveness of cisplatin-based and carboplatin-based chemotherapy for treatment of advanced urothelial carcinoma. Ann Oncol 23: 406-410, 2012.

5. Shimada M, Itamochi H and Kigawa J: Nedaplatin: A cisplatin derivative in cancer chemotherapy. Cancer Manag Res 5: 67-76, 2013.
6. Akaza H, Togashi M, Nishio Y, Miki T, Kotake T, Matsumura Y, Yoshida $\mathrm{O}$ and Aso Y: Phase II study of cis-diammine(glycolato) platinum, 254-S, in patients with advanced germ-cell testicular cancer, prostatic cancer, and transitional-cell carcinoma of the urinary tract. 254-S urological cancer study group. Cancer Chemother Pharmacol 31: 187-192, 1992.

7. Kuroda M, Kotake T, Akaza H, Hinotsu S and Kakizoe T: Efficacy of dose-intensified MEC (methotrexate, epirubicin and cisplatin) chemotherapy for advanced urothelial carcinoma: A prospective randomized trial comparing MEC and M-VAC (methotrexate, vinblastine, doxorubicin and cisplatin). Japanese urothelial cancer research group. Jpn J Clin Oncol 28: 497-501, 1998.

8. von der Maase H, Hansen SW, Roberts JT, Dogliotti L, Oliver T, Moore MJ, Bodrogi I, Albers P, Knuth A, Lippert CM, et al: Gemcitabine and cisplatin versus methotrexate, vinblastine, doxorubicin, and cisplatin in advanced or metastatic bladder cancer: Results of a large, randomized, multinational, multicenter, phase III study. J Clin Oncol 18: 3068-3077, 2000.

9. Matsuo S, Imai E, Horio M, Yasuda Y, Tomita K, Nitta K, Yamagata K, Tomino Y, Yokoyama $\mathrm{H}$ and Hishida A; Collaborators developing the Japanese equation for estimated GFR: Revised equations for estimated GFR from serum creatinine in Japan. Am J Kidney Dis 53: 982-992, 2009.

10. Eisenhauer EA, Therasse P, Bogaerts J, Schwartz LH, Sargent D, Ford R, Dancey J, Arbuck S, Gwyther S, Mooney M, et al: New response evaluation criteria in solid tumours: Revised RECIST guideline (version 1.1). Eur J Cancer 45: 228-247, 2009.

11. Alfred Witjes J, Lebret T, Compérat EM, Cowan NC, De Santis M, Bruins HM, Hernández V, Espinós EL, Dunn J, Rouanne M, et al: Updated 2016 EAU guidelines on muscle-invasive and metastatic bladder cancer. Eur Urol 71: 462-475, 2017.

12. Shinohara N, Harabayashi T, Suzuki S, Nagao K, Seki H, Murakumo M, Mitsuhashi K, Demura T, Nagamori S, Matsuyama $\mathrm{H}$, et al: Salvage chemotherapy with paclitaxel, ifosfamide, and nedaplatin in patients with urothelial cancer who had received prior cisplatin-based therapy. Cancer Chemother Pharmacol 58: 402-407, 2006.

13. Kitamura H, Taguchi K, Kunishima Y, Yanase M, Takahashi A, Shigyo M, Tanaka T, Mutoh M, Fukuta F, Masumori N and Tsukamoto T: Paclitaxel, ifosfamide, and nedaplatin as second-line treatment for patients with metastatic urothelial carcinoma: A phase II study of the SUOC group. Cancer Sci 102: 1171-1175, 2011.

14. Umemoto S, Miyoshi Y, Nakaigawa N, Makiyama K, Ogawa T, Uemura $\mathrm{H}$, Yao $\mathrm{M}$ and Kubota $\mathrm{Y}$ : A pilot study of combination chemotherapy of gemcitabine and nedaplatin for urological cancer. Jpn J Clin Urol 61: 903-908, 2007.

15. Matsumoto M, Takeda Y, Maki H, Hojo K, Wada T, Nishitani Y, Maekawa R and Yoshioka T: Preclinical in vivo antitumor efficacy of nedaplatin with gemcitabine against human lung cancer. Jpn J Cancer Res 92: 51-58, 2001.

16. Tian Y, Liu Q, Wu K, Chu Q, Chen Y and Wu K: Meta-analysis comparing the efficacy of nedaplatin-based regimens between squamous cell and non-squamous cell lung cancers. Oncotarget 8 : 62330-62338, 2017. 